\title{
Selection of Solvent Load and First-Stage Pressure To Reduce Interference Effects in Inductively Coupled Plasma-Mass Spectrometry
}

\author{
Barbara S. Ross and Gary M. Hieftje \\ Department of Chemistry, Indiana University, Bloomington, Indiana, USA
}

In inductively coupled plasma-mass spectrometry the furst-stage pressure and solvent characteristics can strongly influence spectral and nonspectroscopic interference effects. By manipulating the pressure and solvent load, one can regulate the degree of analyte signal suppression observed in the presence of high concentrations $(<10 \mathrm{mM})$ of concomitants. Importantly, the same operating conditions that eliminate the matrix effects maintain the analytical utility of the system. However, for some interferent-analyte combinations, the identity of the concomitant anion and subsequent $\mathrm{pH}$ of the solution determine whether the interference effects can be eliminated entirely. The first-stage pressure does not appear to significantly affect the oxide-ion and doubly charged ion ratios; the solvent characteristics are the dominant factors that dictate these ratios. (J Am Soc Mass Spectrom 1992, 3, 128-138)

S ince its introduction, the technique of inductively coupled plasma-mass spectrometry (ICPMS) has gained widespread acceptance for elemental and isotopic analysis. Superior detection limits, spectral simplicity, and almost complete elemental coverage across the periodic table are some of the reasons for this popularity [1-3]. However, numerous shortcomings of the technique have been described. One such problem area has been spectral and sample-matrix interference [1-7].

Matrix interference effects have been the subject of investigation [5, 8-14] and review [1-3]. Although extensive studies have been devoted to documentation of the interferences, the question of where and why they arise is not fully understood. Additionally, it is not clear why the matrix effects differ among the various systems $[5,11-16]$, or why they are generally more severe in ICP-MS than in inductively coupled plasma-optical emission spectrometry (ICP-OES) $[6,9$, $12,13,17]$.

Spectral (isobaric) interferences arising from oxide and doubly charged ions have been widely reported in ICP-MS as well $[4-7,18,19]$. These ions are present at appreciable levels for elements that have low second ionization potentials or high oxide-bond energies. Although a growing list of these spectral interferences is being assembled $[4,5,13,19,20]$, the

Address reprint requests to Gary M. Hieftje, Department of Chemistry, Indiana University, Bloumington, IN 47405. question of whether the plasma or interface conditions cause them is still unresolved.

In the present study an attempt is made to overcome both spectral and matrix interferences by adjusting the solvent load and first-stage pressure in a three-stage ICP-MS instrument. Not only have these adjustments reduced the interferences markedly, they have also indicated that mass-dependent interferences are influenced by conditions in the first-stage region of the instrument. Moreover, a set of operating conditions is identifed under which interferences are diminished but sensitivity is retained.

\section{Experimental}

\section{Instrumentation}

The ICP-MS instrument used in the present study is a laboratory-constructed device that has been described in detail elsewhere [21]. Only a few significant modifications have been made. For the pressure study, a capacitance manometer (type 122A, MKS Instruments, Andover, MA) was used to measure the first-stage pressure and was attached directly to the interface. During customary operation the first-stage region is held at 2.0 torr by a two-stage rotary-vane pump (model DUO 060, Arthur Pfeiffer Vakuumtechnik, Asslar, Germany). To further reduce the firststage pressure, a two-stage rotary-vane pump (model DUO 120, Arthur Pfeiffer Vakuumtechnik) was at- 
tached to the interface through two additional ports. A butterfly valve was employed to adjust the firststage pressure by throttling the flow to the larger pump. This modified system has been described in more detail elsewhere [22].

A commercial low-flow MAK torch (model 2500, Sherritt Gordon Mines, Ltd., Fort Saskatchewan, Alberta, Canada) was used in the present study. A detailed list of the operating conditions can be found in Tables 1 and 2. The optimal nebulizer flow rate is defined as the one that produced the maximum analyte ion signal for the majority of analyte species.

A simple flow injection analysis (FIA) system was used for all of the matrix effect work. The matrix solutions were introduced by flow injection to minimize deposition on the sampling and skimming cones and to reduce memory effects. The FIA system was assembled from a six-port injection valve with a $50-\mu \mathrm{L}$ sample loop. The resulting dispersion, defined as the steady-state (conventional) signal divided by the signal obtained with FLA, was between 1 and 2 for all analytes investigated. Distilled deionized (DDI) water was delivered with a peristaltic pump (Gilson model Minipuls 2, Gilson Medical Electronics, Inc., Middletown, WI) at a rate of $1.0 \mathrm{~L} / \mathrm{min}$. Switching between FLA and continuous-flow injection was accomplished simply by removing the injection valve. With both introduction methods, the sample is sent through a Meinhard-style concentric glass nebulizer housed in a Scott-type spray chamber with a surrounding cooling jacket. Both the spray chamber and nebulizer were constructed in-house. The wall temperature of the chamber was controlled to $\pm 0.1{ }^{\circ} \mathrm{C}$ with a temperature-regulated, recirculating-water, refrigerating-heating system. The spray chamber was typically located inside the torch box assembly. However, to determine whether the location influenced solvent, aerosol, and performance characteristics, the spray chamber was positioned outside the torch box for some experiments, which necessitated the addition of a length of tubing to connect the chamber to the plasma torch.

Table 1. ICP-MS operating conditions

\begin{tabular}{ll}
\hline Rf generator frequency & $27.12 \mathrm{MHz}$ \\
Applied if power & $1.35 \mathrm{~kW}$ \\
Torch & Low-flow MAK \\
Outer flow & $11.0 \mathrm{~L} / \mathrm{min}$ \\
Intermediate flow & $1.00 \mathrm{~L} / \mathrm{min}$ \\
Inner (nebulizerl flow & Optimized independently (see text) \\
Sample-introduction rate & $1.0 \mathrm{~mL} / \mathrm{min}$ \\
Load-coil design & Grounded at end nearest sampling \\
& plate \\
Sampling depth & $10 \mathrm{~mm}$ above the load coil \\
Sampling cone & Copper, 1.0 -mm orifice \\
Skimming cone & Stainless steel, 1.0-mm orifice \\
& located $10 \mathrm{~mm}$ upstream from \\
& sampler
\end{tabular}

Abbreviation: $\mathbf{R f}=$ radiofrequency .
Table 2. Optimal nebulizer flow rates at different first-stage pressures

\begin{tabular}{|c|c|c|c|c|c|c|}
\hline \multirow{3}{*}{$\begin{array}{l}\text { First-stage } \\
\text { pressure } \\
\text { (torr) }\end{array}$} & \multicolumn{6}{|c|}{ Optimal nebulizer flow rate $(\mathrm{L} / \mathrm{min})$} \\
\hline & \multicolumn{2}{|c|}{$\begin{array}{c}\text { Water-cooled } \\
\text { spray } \\
\text { chamber }\end{array}$} & \multicolumn{2}{|c|}{$\begin{array}{c}\text { Water-cooled } \\
\text { sprey } \\
\text { chamber }\end{array}$} & \multicolumn{2}{|c|}{$\begin{array}{c}\text { Desolvation } \\
\text { system }\end{array}$} \\
\hline & $5^{\circ} \mathrm{C}$ & $15^{\circ} \mathrm{C}$ & $5^{\circ} \mathrm{C}$ & $15^{\circ} \mathrm{C}$ & $5^{\circ} \mathrm{C}$ & $15^{\circ} \mathrm{C}$ \\
\hline 1.0 & 1.00 & & 1.04 & & 1.07 & \\
\hline 2.0 & 0.99 & & 1.03 & & 1.07 & \\
\hline 3.0 & 0.98 & 0.97 & 1.02 & 0.99 & 1.07 & 1.03 \\
\hline
\end{tabular}

"Listed temperature is that of spray chamber (positioned inside torch box].

Listed temperature is that of spray chamber (positioned outside tarch box).

'Listed temperature is that of cooling water through the condenser column.

An alternative sample-introduction system was utilized for comparison. A desolvation system was added to the Scott-type spray chamber, which was no longer water-cooled and with its water jacket emptied. The desolvation system consisted of a heated column, which was operated at $200{ }^{\circ} \mathrm{C}$, and a water-cooled condenser column; the arrangement has been described in detail by Deutsch and Hieftje [23]. The water-recirculating system employed previously to cool the spray chamber was used with the desolvation system to regulate the condenser temperature.

The experimental system used to determine differences in primary and tertiary aerosol production was similar to that utilized by Smith and Denton [24]. In this apparatus, the beam from a He-Ne laser (model 145-01, Spectra Physics, Mountain View, CA) was passed through the aerosol flow and the resulting scattering was measured. First, the tubing ordinarily attached to the plasma torch was removed and placed $\sim 5 \mathrm{~mm}$ below the laser beam. This spatial separation was to avoid scattering of the laser light from the tubing itself. Next, the scattering signal was measured directly from the tertiary aerosol exiting the top of the spray chamber; of course, this measurement required the removal of the tubing attached to the spray chamber. Finally, to measure scattering from the primary aerosol, the glass-concentric nebulizer was removed from the spray chamber setup and placed immediately below the laser beam.

The scattered laser light from the aerosols was detected at $90^{\circ}$ with a photodiode (UV 100, United Detector Technology, Hawthorne, CA) equipped with a laboratory-built housing and amplifer. The detector output was fed to a digital oscilloscope (model 3091, Nicolet Instruments Corp., Madison, WI) and was then downloaded and saved on an IBM-XT computer.

\section{Procedures}

During scattering-based measurements of the primary and tertiary aerosols, a scattering signal and background signal were each collected for $20 \mathrm{~s}$ at a sam- 
pling frequency of $200 \mathrm{~Hz}$. The net scattering attributable to the aerosol was determined by subtracting the integrated background level from the integrated scattering signal, which was then divided by the total number of points collected.

For the matrix-effect studies, the analyte ion signal from each sample solution was determined at the major isotope peak. Background levels at the analyte mass were determined and subtracted by injection of the appropriate concomitant solution with no analyte present. After the injection of each interferent-analyte solution, replicate injections of a solution containing only the analyte were made until two successive injections revealed the absence of memory effects. Peak heights, with background subtracted, were recorded after each injection. The ratio of the average analyte ion signal in the presence of a concomitant species to the average of the two preceding injections of the analyte standard was calculated for each matrix solution to provide a measure of analyte recovery in the presence of the interferent. At least two trials were performed for each concomitant species.

The solvent load (i.e., tertiary aerosol and water vapor collected) which enters the plasma was determined by replacement of the plasma torch with a "U-tube" silica-gel trap. The solvent loading was determined by gravimetric analysis of the silica gel.

\section{Reagents}

Sample solutions were prepared by dilution of commercial atomic absorption standard solutions (1000 $\mu \mathrm{g} / \mathrm{mL}$ ) with DDI water. The reagents have been described in detail elsewhere [25]. Solutions for the interference study contained $10 \mu \mathrm{M}$ analyte in the presence of $10 \mathrm{mM}$ concomitant cation and were prepared with DDI water according to the methods of Dean and Rains [26]. The compounds used to prepare the concomitant solutions are listed in Table 3. All chemicals used were reagent grade. Analyte reference standards were prepared in DDI water at the same analyte ion concentration $(10 \mu \mathrm{M})$ used in the interferent solutions.

Table 3. Compounds used for concomitant-cation solutions

\begin{tabular}{lrl}
\hline Cation & $\begin{array}{l}\text { Atomic } \\
\text { weight }\end{array}$ & \multicolumn{1}{c}{ Compound } \\
\hline \hline $\mathrm{Sr}^{\mathrm{a}}$ & 87.3 & $\mathrm{SrCO}_{3}$ \\
$\mathrm{Ba}$ & 137.3 & $\mathrm{BaCl}_{2} \cdot 2 \mathrm{H}_{2} \mathrm{O}$ \\
$\mathrm{Ba}$ & 137.3 & $\mathrm{BaCO}_{3}$ \\
$W$ & 183.8 & $\mathrm{Na}_{2} \mathrm{WO}_{4} \cdot 2 \mathrm{H}_{2} \mathrm{O}^{\mathrm{C}}$ \\
$\mathrm{Wb}$ & 207.2 & $\mathrm{~Pb}^{\mathrm{a}}\left(\mathrm{NO}_{3}\right)_{2}$ \\
$\mathrm{U}$ & 238.0 & $\mathrm{UO}_{2}\left(\mathrm{NO}_{3}\right)_{2} \cdot 6 \mathrm{H}_{2} \mathrm{O}$ \\
\hline
\end{tabular}

- Concentrated nitric acid $(10 \mathrm{~mL} / \mathrm{L})$ added to solution

All chemicals were reagent grade.

cNotice that the compaund used to introduce $W$ as a concomitant contains a 2:1 ratio of $\mathrm{Na} / \mathrm{W}$, so the presence of $\mathrm{Na}$ could also produce an interference.

\section{Results and Discussion}

\section{Characterization of Primary and Tertiary Aerosol Production}

For all sample-introduction arrangements, an increase in cooling water temperature produced an increase in the measured solvent loading, as shown in Table 4. Coincidentally, a nearly equivalent solvent load was introduced into the plasma with the water-cooled spray chamber (WCSC) held at $5{ }^{\circ} \mathrm{C}$ and by the desolvation system with its condenser operated at $15^{\circ} \mathrm{C}$. However, because the silica gel trap collects both water vapor and aerosol, its weight yields only total solvent load information; the fraction of solvent vapor and aqueous aerosol in the two situations might be rather different. Therefore, scattering experiments were used to determine the nature of the aerosol that is produced by the several sample-introduction arrangements.

The use of a 632.8-nm laser wavelength produces efficient scattering from droplets ranging in size from 0.1 to $10 \mu \mathrm{m}$ [24]. With the desolvation system in place there was no measurable scattering signal from the flow exiting the condenser column. Therefore, it can be assumed that the mean diameter of the droplets at this point was $<\sim 0.1 \mu \mathrm{m}$. With such a fine aerosol, it is predominantly the amount of water vapor that is influenced by a change of condenser temperature and contributes to the subsequently measured solvent loading.

Previous studies have shown that, with a Scott-type spray chamber, higher cooling water temperatures raise water loading into the plasma in a predictable manner [28, 29]. As shown in Figure 1, the aerosol exiting the WCSC produced a scattering signal that increased with spray chamber temperature. This increased signal is attributable to a larger cutoff diameter of the spray chamber, produced in turn by its higher temperature. With a larger cutoff diameter [30, 31], the chamber passes a greater fraction of the larger droplets produced within it. These findings show that the spray chamber temperature influences not only water vapor loading, but also aerosol characteristics.

The addition of a length of tubing (intended eventually to enable the spray chamber to be positioned

Table 4. Plasma solvent loading ${ }^{\mathrm{a}}$ ( $\mathrm{mg} / \mathrm{min}$ )

\begin{tabular}{rccc}
$\begin{array}{c}\text { Temperature } \\
\left({ }^{\circ} \mathrm{C}\right)\end{array}$ & $\begin{array}{c}\text { Water-cooled } \\
\text { spray } \\
\text { chamber }^{\text {b }}\end{array}$ & $\begin{array}{c}\text { Water-cooled } \\
\text { spray } \\
\text { chamber }^{c}\end{array}$ & $\begin{array}{c}\text { Desolvation } \\
\text { system }^{\text {d }}\end{array}$ \\
\hline 5 & 17 & 17 & $\begin{array}{c}8.07 \\
15\end{array}$ \\
\hline
\end{tabular}

${ }^{a}$ Nebulizer flow adjusted to optimal value for a first-stage pressure of 3 torr (see Table 2).

'Silica gel trap attached directly to spray chamber.

Tubing 118 in.l attached between silica gel trap and spray chamber.

${ }^{d}$ Listed temperature is that of cooling water through the condenser column. 


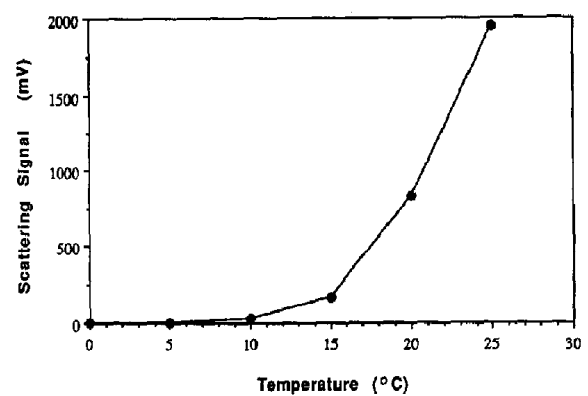

Figure 1. Effect of spray chamber temperature on the scattering signal of tertiary aerosol directly exiting the top of the chamber. He-Ne laser $(632.8 \mathrm{~nm})$ used as scattering light source. Spray chamber placed outside housing.

outside the torch housing) between the chamber and the torch reduced the scattering signal, although the total solvent load was not significantly altered (Table 4). Similarly, the aerosol directly exiting the spray chamber was more clearly visible than that which was sent through the additional tubing. These differences suggest that the mean droplet size was reduced when the tubing (18 in.) was placed between the spray chamber and plasma torch. It appears that the tubing effectively acts as an evaporation column and is responsible for the different aerosol characteristics.

These differences in aerosol characteristics no doubt influence the optimal nebulizer flow rates listed in Table 2. At a particular first-stage pressure, a sampleintroduction arrangement that produced a lower solvent load permitted a higher optimal nebulizer flow. As will be shown later, this tradeoff probably results in an optimal total solvent load into the ICP-MS interface. As shown in Figure $2 \mathrm{~A}$, the scattering signal from the tertiary aerosol increased with nebulizer flow rate and is probably caused by a similar increase in primary aerosol production, as seen in Figure 2B. The larger signal measured at the higher nebulizer flows is probably a result of a greater number of droplets being generated; previous work has shown that higher nebulizer flow rates reduce the mean droplet size of both the primary and tertiary aerosols [32].

From these findings, the solvent-delivery characteristics can be quite different among various sampleintroduction arrangements, even though the total solvent loading is comparable. The scattering experiments have shown that with the desolvation system in place, only water vapor and extremely small aerosol droplets are introduced into the discharge; consequently, higher condenser temperatures serve primarily to raise the water vapor loading. When a length of tubing is used in place of the desolvation system and the spray chamber is water-cooled, both the solvent load and droplet size are increased. Further increases in droplet size and a larger ratio of aerosol to water vapor arise when the tubing is removed and the spray
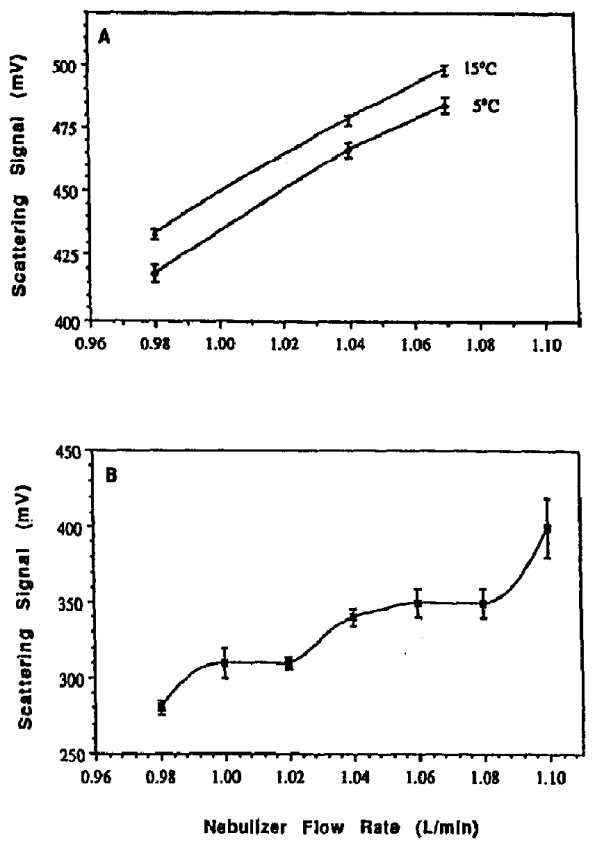

Figure 2. Effect of nebulizer flow rate on the measured aerosol scattering signal: (A) Scattering from tertiary aerosol (watercooled spray chamber held at 5 and $15^{\circ} \mathrm{C}$ ) and (B) scattering from primary aerosol.

chamber is connected directly to the plasma torch. Adjustment of the spray chamber temperature also affects droplet size, aerosol loading, and water vapor loading in a predictable manner. The following studies will reveal how these alternative sample-introduction arrangements and solvent-loading conditions influence spectral interferences, matrix interferences, and sensitivities.

\section{Effect of Concomitant Cations and Anions on Nonspectroscopic Interferences}

Matrix effects caused by both concomitant cations and anions were observed. Barium $(10 \mathrm{mM})$, a high atomic weight element, was used as the concomitant cation and the concomitant anions were $\mathrm{NO}_{3}^{-}$and $\mathrm{Cl}^{-}$(see $\mathrm{Ba}$ in Table 3). The analyte ions ( $\mathrm{Al}, \mathrm{Mo}, \mathrm{Cd}, \mathrm{Ce}$, and Bi) were all present at a concentration of $10 \mu \mathrm{M}$. The data were acquired under "normal" operating conditions (the WCSC $\left[5^{\circ} \mathrm{C}\right]$ positioned inside the torch box and with a first-stage pressure of 2 torr). A recovery of $100 \%$ represents the signal from an analyte in the absence of any concomitant.

Matrix effects for the various analyte elements are shown in Figure 3. It is clear that the presence of a high concentration of Ba suppressed all the signals. 


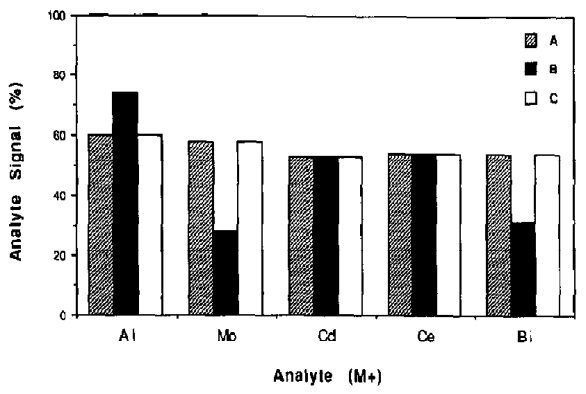

Figure 3. Recovery of signals for $\mathrm{Al}^{+}, \mathrm{Mo}^{+}, \mathrm{Cd}^{+}, \mathrm{Ce}^{+}$, and $\mathrm{Bi}^{+}(10 \mu \mathrm{M})$ in the presence of $10 \mathrm{mM}$ Ba in (A) $0.1 \% \mathrm{HNO}_{3}$, (B) $20 \mathrm{mM} \mathrm{Cl}$, and (C) $20 \mathrm{mM} \mathrm{Cl}$ and $0.1 \% \mathrm{HNO}_{3}$. A water-cooled spray chamber (positioned inside the torch box) at $5{ }^{\circ} \mathrm{C}$ and a first-stage pressure of 2 torr were used. An analyte signal of $100 \%$ represents the value in the absence of any concomitant.

However, for $\mathrm{Al}, \mathrm{Mo}$, and $\mathrm{Bi}$ the degree of suppression depended on the particular anion that was present. For Mo and Bi, the matrix containing $\mathrm{Ba}$ and $\mathrm{Cl}$ caused approximately twice the analyte signal suppression that was observed for $\mathrm{Ba}$ in $0.1 \% \mathrm{HNO}_{3}$. The opposite effect was observed for $\mathrm{Al}$, where a greater signal suppression was obtained in the presence of $0.1 \% \mathrm{HNO}_{3}$ than when $\mathrm{Cl}$ was present alone.

It is believed that the greater suppression observed for the barium chloride solution is attributable indirectly to $\mathrm{pH}$ effects. The barium chloride solution in distilled water had a $\mathrm{pH}$ of 5 , whereas those solutions made in $0.1 \% \mathrm{HNO}_{3}$ were at a $\mathrm{pH}$ of 1 . Not only does the $\mathrm{pH}$ influence analyte solubility, but ion complexity and its degree of protonation. For example, aluminum is present as a trihydroxide species at a $\mathrm{pH}$ of 5 , but as hydrated $\mathrm{Al}^{+3}$ ions at a $\mathrm{pH}$ of 1 . Similarly, for $\mathrm{Mo}, \mathrm{pH}$ determines not only the degree of protonation, but whether Mo is in solution as an isopolymolybdate or mononuclear species [33]. In addition, the absolute concentration of Mo dictates the size and to what degree these polymolybdate species are formed [33]. Similarly, Bi will be present in different forms, depending on the $\mathrm{pH}$ of the solution. Thus, the $\mathrm{pH}$ can determine what species are formed and to what degree they can interact with the other species present. These factors then affect how efficiently the sample can be atomized and ionized in the plasma, which in turn can influence the degree of matrix interferences that occur.

From the above arguments it appears that previously cited discrepancies $[5,11-16,27]$ concerning the severity and direction of observed interferences might be due in part to solution effects and not only to plasma or interface conditions. This is particularly true for those studies that were performed on the same ICP-MS systems, but which show different matrix effects $[5,11-16,27]$.

Of course, solution and $\mathrm{pH}$ effects should be con- sidered also when interferences are examined in ICPOES. Unfortunately, the majority of interference studies in ICP-OES have neglected to report the reagents used to prepare matrix solutions. It would seem to be beneficial to both the ICP-OES and ICP-MS communities to investigate these solution effects further.

\section{Effect of First-Stage Pressure and Solvent Loading on Nonspectroscopic Interferences}

Molybdenum was selected as the first analyte to be tested because it has a moderate mass $(98 \mathrm{u}$ for the most abundant isotope) and ionization potential (7.10 $\mathrm{eV}$ ) and would therefore be expected to exhibit most of the kinds of interferences reported in ICP-MS. The matrix effects on Mo signals from equimolar concentrations of five interferents $(\mathrm{Sr}, \mathrm{Ba}, \mathrm{W}, \mathrm{Pb}$, and $\mathrm{U}$ ) were initially measured. These elements were chosen because they cover a broad mass range and can illustrate the previously shown mass dependence of the matrix effects; the greater the mass of the concomitant species, the greater the signal suppression $[8,10-14$, $27]$. Again, a recovery of $100 \%$ represents the signal from the analyte in the absence of any concomitant. First-stage pressures $>3$ torr were not investigated because of limited vacuum-pumping capabilities and the resulting significant increase in second- and third-stage pressures.

Operation with desolvation system. The desolvation system was first used with the condenser at $5^{\circ} \mathrm{C}$, to indicate performance under conditions of lowest solvent load (see Table 4). The resulting influence of first-stage pressure on Mo recovery in the presence of various concomitants is shown in Figure 4. At all first-stage pressures that were tested, the previously mentioned dependence of the analyte suppression on concomitant mass was observed. However, there was a drastic difference among the signals obtained at the individual first-stage pressures. The suppression was most severe at 2 torr, which is the usual operating

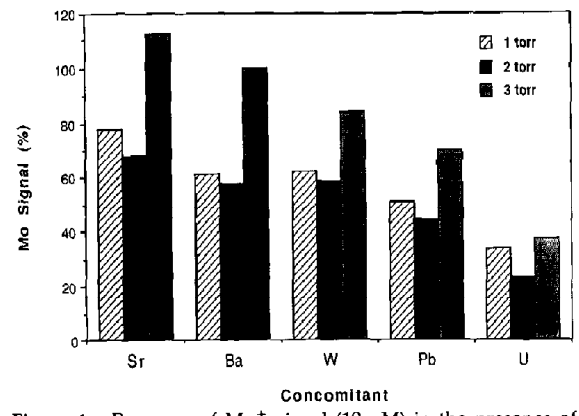

Figure 4. Recovery of $\mathrm{Mo}^{+}$signal $(10 \mu \mathrm{M})$ in the presence of $10 \mathrm{mM} \mathrm{Sr}, \mathrm{Ba}, \mathrm{W}, \mathrm{Pb}$, and $\mathrm{U}$ at various first-stage pressures while using a desolvation system (condenser temperature $5^{\circ} \mathrm{C}$ ). 
pressure for our ICP-MS instrument. At either higher or lower first-stage pressures, the Mo signal suppression is lessened for all of the concomitants shown in Figure 4, with the best recovery at 3 torr.

When the amount of water vapor loading was increased by raising the temperature of the condenser in the desolvation system (to $15{ }^{\circ} \mathrm{C}$; see Table 2), the observed matrix interferences were generally lessened. Because of the improved signal recoveries at higher first-stage pressures noted above, 3 torr was utilized. As listed in Table 5, the effect of greater water vapor loading was most noticeable for those solutions containing heavier concomitants, although signal suppression was still significant. Thus, a higher first-stage pressure and increased water vapor loading can be used to reduce the observed matrix effects, but not to eliminate them.

Water-cooled spray chamber outside the torch box. The desolvation system was removed and the spray chamber was cooled to $5{ }^{\circ} \mathrm{C}$, positioned outside the torch box, and connected to the plasma torch with a length of tubing. Under these conditions the water vapor loading is relatively light (see Table 4) and the aerosol droplets quite small. With this configuration, the same influence of first-stage pressure on Mo recovery was observed (Figure 5) as with the desolvation system in place (Figure 4); the greatest loss of Mo signal occurred at a pressure of $\mathbf{2}$ torr and the highest recovery at 3 torr. The degree of the suppression also was again dictated by the mass of the concomitant species. Generally, at the lower first-stage pressures (1 and 2 torr), the reduction in signal observed with the WCSC was greater than with the desolvation system. However, when the pressure was raised to 3 torr, the Mo signal recovery was improved (Figure 5) to the point

Table 5. Influence of cooling water temperature on the severity of matrix interference for Mo analyte ion signal ${ }^{a}$

\begin{tabular}{|c|c|c|c|c|c|c|}
\hline \multirow{3}{*}{$\begin{array}{l}\text { Matrix } \\
\text { system } \\
\text { Cation }\end{array}$} & \multicolumn{6}{|c|}{ Molybdenum signal $(\%)^{\mathrm{b}}$} \\
\hline & \multicolumn{2}{|c|}{$\begin{array}{l}\text { Water-cooled } \\
\text { spray chamber } \\
\text { inside } \\
\text { torch box }\end{array}$} & \multicolumn{2}{|c|}{$\begin{array}{l}\text { Water-cooled } \\
\text { spray chamber } \\
\text { outside } \\
\text { torch box }\end{array}$} & \multicolumn{2}{|c|}{$\begin{array}{l}\text { Desolvation } \\
\text { system } \\
\text { condenser } \\
\text { temperature }\end{array}$} \\
\hline & $5{ }^{\circ} \mathrm{C}$ & $15^{\circ} \mathrm{C}$ & $5^{\circ} \mathrm{C}$ & $15^{\circ} \mathrm{C}$ & $5^{\circ} \mathrm{C}$ & $15^{\circ} \mathrm{C}$ \\
\hline$\overline{\mathrm{Sr}}$ & 97 & 100 & 95 & 104 & 112 & 116 \\
\hline $\mathrm{Ba}^{\mathrm{c}}$ & 95 & 106 & 88 & 100 & 100 & 99 \\
\hline$W$ & 86 & 120 & 74 & 79 & 84 & 91 \\
\hline $\mathrm{Pb}$ & 80 & 118 & 75 & B1 & 70 & 85 \\
\hline$U$ & 53 & 106 & 29 & 48 & 37 & 56 \\
\hline
\end{tabular}

${ }^{a}$ Mo present as analyte at $10 \mu \mathrm{M}$; concomitant elements added at $10 \mathrm{mM}$.

${ }^{b}$ First-stage pressure at 3 torr. The nebulizer flow rate was adjusted for maximum signal when either the sample-introduction system or cooling water temperature was changed. The relative standard deviation averaged $\pm 3 \%$ for the matrix solutions mea sured under a selected set of conditions. A signal of $100 \%$ repre sents the analyte signal in the absence of any concomitant.

"Solution was made in $0.1 \%(\mathrm{~V} / \mathrm{V})$ nitric acid.

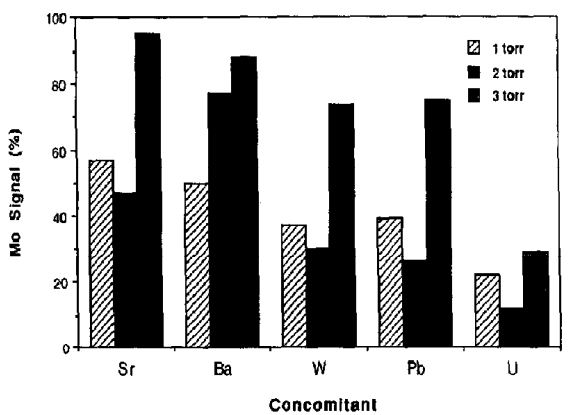

Figure 5. Recovery of $\mathrm{Mo}^{+}$signal $(10 \mu \mathrm{M})$ in the presence of $10 \mathrm{mM} \mathrm{Sr}, \mathrm{Ba}, \mathrm{W}, \mathrm{Pb}$, and $\mathrm{U}$ at various first-stage pressures while using a water-cooled spray chamber held at $5{ }^{\circ} \mathrm{C}$ and positioned outside of the torch box.

that it was approximately equal to that measured when the desolvation system was in place (Figure 4).

With the WCSC positioned outside the torch box, the interference effects were generally further reduced when the spray chamber temperature was increased to $15{ }^{\circ} \mathrm{C}$, as seen from the values listed in Table 5 . Moreover, a greater Mo signal was obtained when solvent load was raised. With both the WCSC and the desolvation system, it appears that increased solvent loading can alleviate matrix interferences.

Water-cooled spray chamber inside the torch box. The influence of first-stage pressure on the measured analyte signal was determined by using the operating conditions listed in Table 1 and with the $5{ }^{\circ} \mathrm{C}$ WCSC located inside the torch box. In this configuration the total solvent load is about the same as when the spray chamber is located outside the torch housing; however, the mean aerosol droplet size that enters the ICP torch is somewhat larger. As shown in Figure 6, the signal recovery then improved progressively with first-stage pressure. Indeed, the interference at 1 torr was worse than that measured with the other

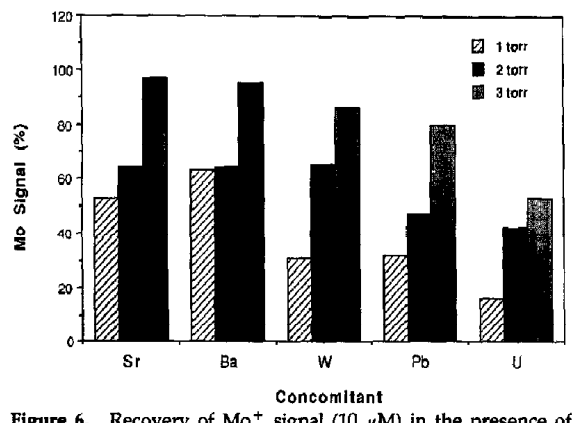

Figure 6. Recovery of $\mathrm{Mo}^{+}$signal $(10 \mu \mathrm{M})$ in the presence of $10 \mathrm{mM} \mathrm{Sr}, \mathrm{Ba}, \mathrm{W}, \mathrm{Pb}$, and $\mathrm{U}$ at various first-stage pressures while using a water-cooled spray chamber held at $5{ }^{\circ} \mathrm{C}$ and positioned inside of the torch box. 
sample-introduction configurations but much less than with the others at first-stage pressures of 2 and 3 torr. The degree of suppression still depended on the mass of the concomitant species, but was not as severe for the heaviest concomitant as with the other sample-introduction configurations.

With the spray chamber inside the torch box and the cooling water temperature raised to $15{ }^{\circ} \mathrm{C}$, a suppression effect was no longer observed, as seen in Table 5. In fact, an enhancement was observed in the Mo signal in the presence of $\mathrm{W}$ and $\mathrm{Pb}$. Thus, by regulation of the furst-stage pressure and aerosol conditioning, either suppression and enhancement can be produced for the same interferent-analyte combination. For our system, the use of a first-stage pressure of 3 torr and a $15{ }^{\circ} \mathrm{C}$ WCSC placed inside the torch box appears to be optimal for minimizing matrix interference effects.

The increased Mo recoveries obtained by removal of the desolvation system and placement of the spray chamber inside the torch box are a consequence of correspondingly different aerosol characteristics. An increase in water vapor loading alone does not produce the same improvements as when aerosol characteristics are altered. The effect of the spray chamber position is presumed to be a result of the additional tubing between the spray chamber and plasma torch, which acts as a heater column. Thus, even between systems that appear to be identical, interference effects can vary because of a different separation between the plasma torch and spray chamber. The sample introduction system and droplet size have been found to have a strong influence on the magnitude and nature of matrix interferences also in ICP-OES [34-36]. A similar dependence in ICP-MS is therefore not surprising.

This influence of the sample-introduction arrangement on matrix interferences is possibly related in part to "aerosol ionic redistribution" [35]. The work by Borowiec et al. [35] shows that the ratio of major to minor cations present in the aerosol droplets is dependent upon the droplet size. These findings are supported by the results reported by Skogerboe and Freeland [36]. Thus, the differing interference effects among the sample-introduction systems, which produced dissimilar droplet sizes, might be a result in part of a change in the ratio of major to minor ions entering the plasma. This aerosol ionic redistribution could couple with more direct effects of the aerosol on both the plasma and interface conditions which, in turn, cause different matrix interference effects to be measured.

Interference on other analyte species. To determine if a first-stage pressure of 3 torr and a spray chamber temperature of $15{ }^{\circ} \mathrm{C}$ reduces the matrix interference for other interferent:analyte solutions, analyte recoveries were compared to those obtained under "normal" operating conditions ( 2 torr; WCSC at $5^{\circ} \mathrm{C}$ ). In both sets of measurements the spray chamber was

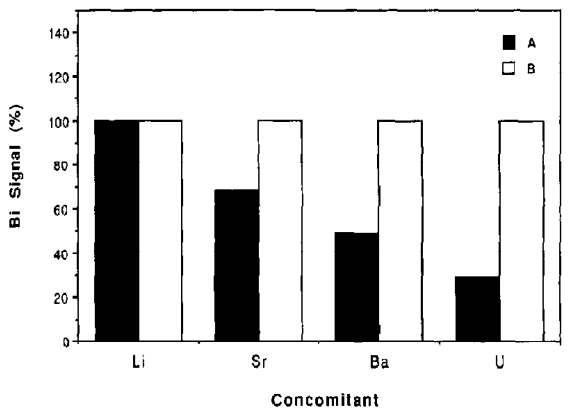

Figure 7. Recovery of $\mathrm{Bi}^{+}$signal $(10 \mu \mathrm{M})$ in the presence of 10 $\mathrm{mM} \mathrm{Li}, \mathrm{Sr}, \mathrm{Ba}$, and $\mathrm{U}$ while using a water-cooled spray chamber (inside the torch box): (A) first-stage pressure at 2 torr and spray chamber temperature at $5{ }^{\circ} \mathrm{C}$ and (B) first-stage pressure at 3 torr and spray chamber temperature at $15{ }^{\circ} \mathrm{C}$.

positioned inside the torch box. The influence of several concomitant cations on a $10 \mu \mathrm{M}$ Bi solution is shown in Figure 7. At a first-stage pressure of 2 torr and cooling water temperature of $5^{\circ} \mathrm{C}$, suppression was usually more severe in the presence of heavy concomitants than with lighter concomitants. However, the matrix effects were eliminated, in all cases, at a higher spray-chamber temperature $\left(15^{\circ} \mathrm{C}\right)$ and first-stage pressure ( 3 torr).

As shown in Figure 8, the influence of a high concentration of barium on various analyte ion signals could also be regulated by proper choice of aerosol character and first-stage pressure. The suppression effects observed for all analytes at a first-stage pressure of 2 torr and with a $5{ }^{\circ} \mathrm{C} \mathrm{WCSC}$ were eliminated when a 3-torr pressure and increased solvent loading were used. In fact, under these conditions, a slight enhancement of $\sim 5-10 \%$ was observed in the $\mathrm{Ce}$ and $\mathrm{Cd}$ recovery.

It can therefore be concluded that the plasma and first-stage conditions can be regulated to control ma-

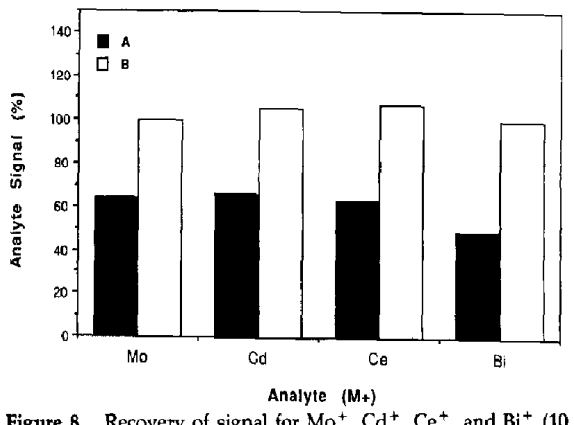

Figure 8. Recovery of signal for $\mathrm{Mo}^{+}, \mathrm{Cd}^{+}, \mathrm{Ce}^{+}$, and $\mathrm{Bi}^{+}(10$ $\mu \mathrm{M}$ ) in the presence of $10 \mathrm{mM} \mathrm{Ba}$ (in $0.1 \% \mathrm{HNO}_{3}$ ) while using a water-cooled spray chamber (inside the torch box): (A) first-stage pressure at 2 torr and spray chamber temperature at $5{ }^{\circ} \mathrm{C}$ and (B) first-stage pressure at 3 torr and spray chamber temperature at $15^{\circ} \mathrm{C}$. 
trix effects induced by high concentrations of concomitants. This regulation is possible in part by altering the first-stage pressure. In all sample-introduction arrangements the highest signal recoveries were measured at a first-stage pressure of 3 torr, revealing that the optimal operating pressure appears to be independent of solvent characteristics. Ultimately, however, it is the combination of first-stage pressure, water vapor loading, and aerosol loading that dictates whether suppression, enhancement, or no change of analyte signal is caused by a concomitant element.

\section{Analyte Sensitivity}

Sensitivities (working-curve slopes) for several analyte elements were measured as a function of firststage pressure and aerosol characteristics. The concentration of each analyte element was $1 \mu \mathrm{g} / \mathrm{mL}$. Data were acquired both with the WCSC located inside the torch box and with a desolvation system in place. When the first-stage pressure or cooling water temperature was changed, the nebulizer flow rate was adjusted to maximize analyte signal. The optimal settings are listed in Table 2.

When the WCSC was employed, a pressure of 2 torr produced the highest sensitivities for the majority of analyte ions, as shown in Figure 9. Only the heavier elements $(\mathrm{Pb}$ and $\mathrm{U})$ appeared not to be strongly influenced by first-stage pressure and yielded approximately equal sensitivities over the pressure range examined. Unfortunately, 2 torr is the pressure at which the interference effects were most severe (Figures 4-6). Importantly, sensitivities generally were reduced by less than a factor of 2 when the first-stage pressure was increased to 3 torn. At this pressure, the advantage gained from reduced matrix effects outweighs any loss in sensitivity for the lighter elements, which are typically the analyte species most influenced by the presence of high concentrations of concomitants [1-3].

The influence of the cooling water temperature on

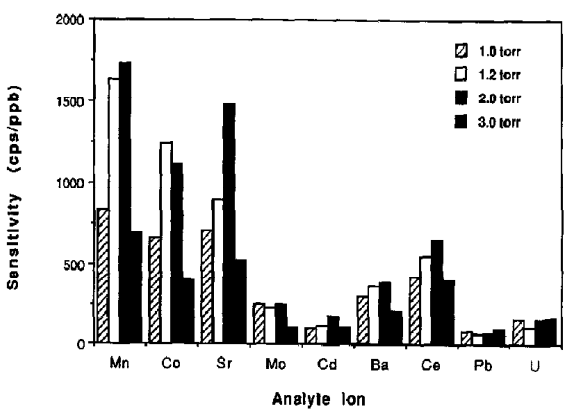

Figure 9. Sensitivities for several elements measured at various first-stage pressures with a water-cooled spray chamber held at $5{ }^{\circ} \mathrm{C}$ and positioned inside the torch box. analyte sensitivities also was measured and is shown in Figure 10 for a first-stage pressure of 3 torr. With the WCSC inside the torch box (Figure 10A), heating of the spray chamber from 5 to $15{ }^{\circ} \mathrm{C}$ altered the measured sensitivities for some elements. The increased solvent loading produced a lower sensitivity for the lighter elements ( $\mathrm{Mn}, \mathrm{Co}$, and $\mathrm{Sr}$ ), but higher sensitivities for the heavier elements $(\mathrm{Ce}, \mathrm{Pb}$, and $\mathrm{U})$. Thus, the use of higher first-stage pressures and greater aerosol loading does compromise somewhat those sensitivities that are already high but helpfully enhances those that were the lowest at a first-stage pressure of 2 torr and a $5{ }^{\circ} \mathrm{C} \mathrm{WCSC}$. When the desolvation system was installed (Figure 10B), a similar pattern emerged; although analyte signals were higher than with the WCSC, a greater solvent load (caused by a higher condenser temperature) lowered sensitivities, especially for the lighter elements.

With the desolvation system in place the optimal first-stage pressure was dependent on analyte mass, as shown in Figure 11; the greater the atomic mass, the higher the optimal pressure. A pressure of 1 torr consistently produced the lowest sensitivities for all the analyte ions. However, ${ }^{55} \mathrm{Mn},{ }^{59} \mathrm{Co}$, and ${ }^{88} \mathrm{Sr}$ exhibited maximum sensitivities at 1.2 torr; ${ }^{98} \mathrm{Mo},{ }^{114} \mathrm{Cd}$, ${ }^{138} \mathrm{Ba}$, and ${ }^{140} \mathrm{Ce}$ at 2 torr; and ${ }^{208} \mathrm{~Pb}$ and ${ }^{238} \mathrm{U}$ at 3 torr. Thus, for heavier elements the best sensitivities were obtained conveniently at the pressure that was found to minimize matrix effects.
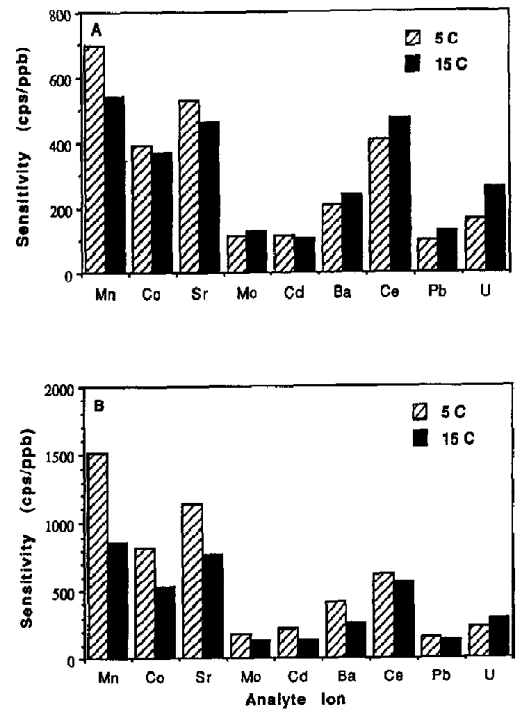

Figure 10. Effect of cooling water temperature at $5^{\circ} \mathrm{C}(\square)$ and $15^{\circ} \mathrm{C}(\square)$ on ion signals measured for various elements (firststage pressure at 3 torr): (A) Water-cooled spray chamber (positioned inside the torch box); water temperature through spray chamber jacket changed; (B) Desolvation system; water temperature through condenser adjusted. Note the scale difference in plots $\mathbf{A}$ and $\mathbf{B}$. 


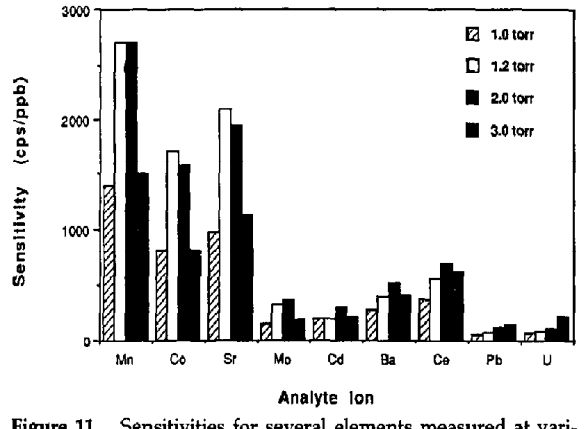

Figure 11. Sensitivities for several elements measured at various first-stage pressures with a desolvation system attached. The condenser temperature was maintained at $5{ }^{\circ} \mathrm{C}$.

When the optimal pressures for the two sample-introduction systems are compared, different mass dependencies are observed. This dissimilarity again suggests that aerosol characteristics and water vapor load influences both interface and plasma conditions. It appears that the location where the first-stage expansion is skimmed (which can be dictated by first-stage pressure) has a large influence on the measured sensitivities when the sample solution is introduced as a combination of very small droplets, dry aerosol, and solvent vapor. This influence is reduced as the solvent load is increased and as aerosol characteristics are changed.

At the present time, it is unclear exactly how the influence of the water on the plasma is related to changes that arise in the interface. Previous ICP-MS research [22, 37-39] has shown that changes in solvent loading influence interface conditions. Also, it is well established that changes in solvent load [40] and the aerosol droplet size [41] alter plasma conditions. In fact, emission studies have shown that increased water vapor loading affects plasma conditions differently than increased aerosol loading [42]. Therefore, it might be changes induced in the plasma by variation of the solvent load that are responsible for altering interface conditions and the subsequent dissimilarities.

\section{Spectroscopic Interferences: Doubly Charged and Oxide-Ion Production}

Oxide-ion ratios. The ability to reduce isobaric interferences from oxide ions through the variation of first-stage pressure and solvent loading was investigated first. The effect of first-stage pressure on the ratio of oxide ion to singly charged ion was measured for both a $5{ }^{\circ} \mathrm{C}$ WCSC positioned inside the torch box (Figure 12A) and for a desolvation system (Figure 12B) with a condenser cooled to $5{ }^{\circ} \mathrm{C}$. For both systems, the lowest ratios were measured at a first-stage pressure of 3 torr, the same pressure that was earlier determined to generate the lowest mass-dependent
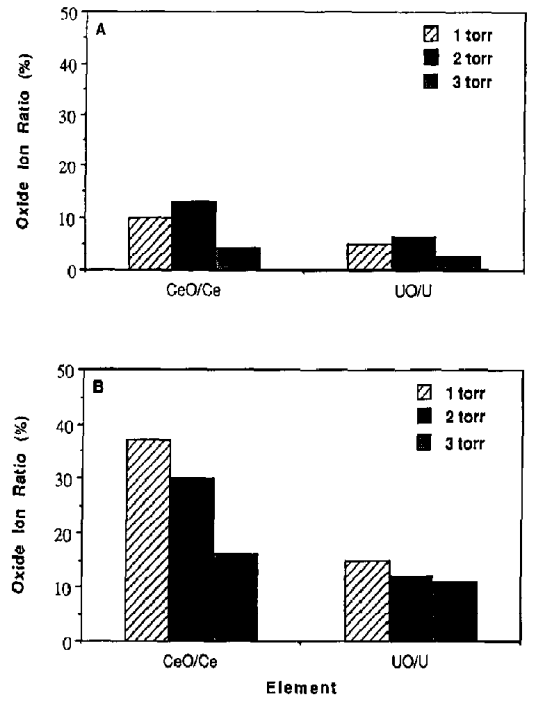

Figure 12. Oxide-ion ratios measured at various first-stage pressures with (A) a water-cooled spray chamber $\left(5^{\circ} \mathrm{C}\right.$; positioned inside the torch box) and (B) a desolvation system (condenser temperature maintained at $5{ }^{\circ} \mathrm{C}$ ).

interferences. However, the configuration of the sample-introduction system and the consequent solvent characteristics appear to alter the degree to which the first-stage pressure influences the ratios. With the WCSC, the ratios obtained at a first-stage pressure of 2 torr were not significantly different from those obtained at 1 torr. In contrast, with the desolvation system, the oxide-ion ratios declined with increased frrst-stage pressure. Overall the oxide-ion ratios obtained with the desolvation system were roughly three times greater than those with the WCSC. These changes are believed not to be caused by a difference in the plasma location from which the ions are extracted. There was no substantial change in the distance between the initial radiation zone and the sampling orifice when the WCSC or desolvation system was in place.

The lower oxide levels measured at 3 torr for both systems suggests that skimming near the Mach disk promotes dissociation of the oxides. Calculations show that a pressure of -3.4 torr places the Mach disk at the tip of the skimming cone [22], located $10 \mathrm{~mm}$ behind the sampling cone. By operating at a pressure of 3 torr, which places the ion skimming very near the Mach disk, there might be greater interaction of the oxide species with the background gases, a reheating of the expanding gas plume, and a greater dissociation or neutralization of the oxide ions. Of course, it would not be surprising if the oxides were dissociated in part also by the skimmer itself, which can become heated if placed within the Mach disk [43]. However, we have noticed in earlier studies that the stainless 
Table 6. Oxide-ion and doubly charged ion ratios obtained under various solvent loading conditions ${ }^{a}$

\begin{tabular}{|c|c|c|c|c|c|c|c|c|}
\hline \multirow{3}{*}{$\begin{array}{l}\text { Analyte } \\
\text { ion }\left(M^{+}\right)\end{array}$} & \multicolumn{4}{|c|}{ Oxide-ion ratio, $\mathrm{MO}^{+} / \mathrm{M}^{+}|\%|$} & \multicolumn{4}{|c|}{ Doubly charged ion ratio, $\mathrm{M}^{++} / \mathrm{M}^{+}(\%)$} \\
\hline & \multicolumn{2}{|c|}{$\begin{array}{l}\text { Desolvation system } \\
\text { condenser temperature }\end{array}$} & \multicolumn{2}{|c|}{$\begin{array}{l}\text { Water-cooled } \\
\text { spray chamber }\end{array}$} & \multicolumn{2}{|c|}{$\begin{array}{l}\text { Desolvation system } \\
\text { condenser temperature }\end{array}$} & \multicolumn{2}{|c|}{$\begin{array}{l}\text { Water-cooled } \\
\text { spray chamber }\end{array}$} \\
\hline & $5^{\circ} \mathrm{C}$ & $15^{\circ} \mathrm{C}$ & $5^{\circ} \mathrm{C}$ & $15^{\circ} \mathrm{C}$ & $5^{\circ} \mathrm{C}$ & $15^{\circ} \mathrm{C}$ & $5^{\circ} \mathrm{C}$ & $15^{\circ} \mathrm{C}$ \\
\hline$\widehat{\mathrm{Sr}}$ & & & & & 5.0 & 4.2 & 4.2 & 3.9 \\
\hline $\mathrm{Ba}^{\mathrm{c}}$ & & & & & 24 & 15 & 15 & 11 \\
\hline $\mathrm{Ce}$ & 16 & 8.1 & 4.2 & 1.3 & 18 & 12 & 13 & 7.4 \\
\hline U & 11 & 4.2 & 2.5 & 1.4 & 12 & 5 & 6.7 & 3.1 \\
\hline
\end{tabular}

steel skimmer becomes characteristically discolored if it is heated. No such discoloration, erosion, or degradation of the skimmer was apparent during or after the studies reported here.

To further explore the influence of solvent load on oxide ratios, the cooling-water temperature was raised, which increased the amount of solvent entering the plasma (Table 4). As listed in Table 6, at a first-stage pressure of 3 torr, the oxide-ion ratios dropped with increased solvent loading with both sample-introduction systems. Because $\mathrm{BaO}^{+}$and $\mathrm{SrO}^{+}$signals were below the detection limit, these ratios were not compared. The similar dependence on the solvent characteristics suggests that it is the influence of water vapor loading (and not aerosol characteristics) on the plasma conditions which leads to the measured reduction. As discussed previously, these changes in plasma conditions might affect behavior in the interface region as well, a supposition that is supported by visually observable changes in emission from the first-stage region when the solvent load is altered.

Other studies have shown that oxide ratios can be decreased [28, 29] or unchanged [28] when the solvent load is reduced or when a different ICP-MS instrument is used [28]. Accordingly, it is hard to draw conclusions regarding what form of aerosol introduction will be optimal when different sample-introduction and interface configurations are compared. The above studies have shown that it is a combination of first-stage pressure, droplet size distribution, and water vapor loading that is important and which dictates the observed trends: a smaller mean droplet size raises oxide ratios, but greater water vapor loading produces lower oxide-ion levels. These factors need to be considered when results obtained from various ICP-MS systems are compared.

Doubly charged ion ratios. The effect of furst-stage pressure on the ratio of doubly charged ion to singly charged ion signals is shown in Figure 13 for both sample-introduction systems operated at $5{ }^{\circ} \mathrm{C}$. The ratios were relatively independent of the interface pressure but were influenced by the solvent load and aerosol droplet size. This behavior is consistent with that noted by Zhu and Browner [28] who also found that first-stage pressure does not influence doubly charged ion ratios. The measured ratios were approximately two to three times greater with the desolvation system in place than with the WCSC inside the torch box.

To further determine the influence of the solvent load and aerosol characteristics, the effect of coolingwater temperature was compared between the two systems. As listed in Table 6, the doubly charged ion levels measured for both sample-introduction systems were lowered when the solvent load was increased; these findings are similar to those for the oxide-ion ratios (see Figure 12 and Table 6). Again, it is appar-
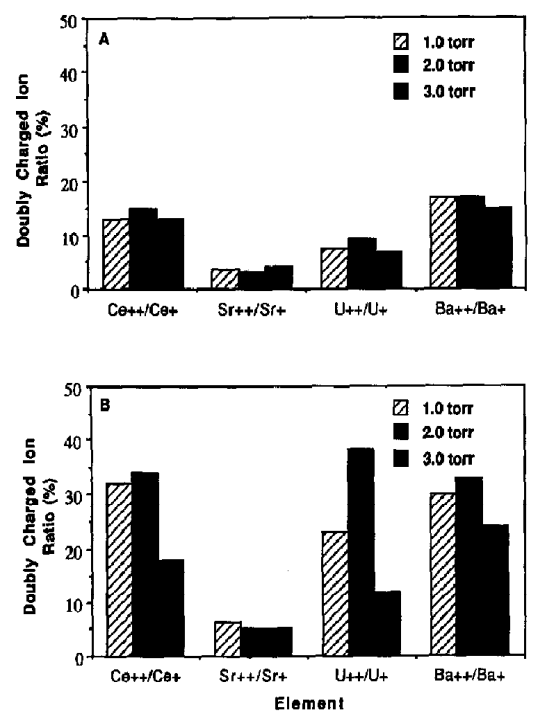

Figure 13. Doubly charged ion ratios measured at various first-stage pressures with (A) a water-cooled spray chamber (5 ${ }^{\circ} \mathrm{C}$; positioned inside the torch box) and (B) a desolvation system (condenser temperature maintained at $5^{\circ} \mathrm{C}$ ). 
ent that the increased water vapor loading is responsible for reducing these levels.

A comparison of the impact of the different sample-introduction arrangements suggests that there might be an optimal droplet size, aerosol burden, and water vapor loading combination which produces plasma conditions that are optimal for singly charged ion production and which minimizes the oxide-ion and doubly charged ion formation. Fortunately, these are the same conditions that also produce the lowest matrix (mass-dependent) interferences. The predominant influence of solvent characteristics suggests that it is the plasma conditions primarily that dictate the measured oxide-ion and doubly charged ion levels in ICP-MS.

\section{Conclusion}

Matrix interferences can be minimized and interferences caused by overlap with peaks from doubly charged and oxide ions can be simultaneously reduced somewhat by operation of an ICP-MS instrument under the proper combination of first-stage pressure, sample-introduction system, and solution composition. Through variation of these factors, a suppression, enhancement, or no influence on the analyte signal can be induced by the presence of a matrix constituent. For our system, operation at a first-stage pressure of 3 torr and the use of a watercooled spray chamber held at $15^{\circ} \mathrm{C}$ (positioned within the torch housing) eliminated the matrix-induced interferences at interferent concentrations not $>10 \mathrm{mM}$. However, for some interferent-analyte combinations, such factors as solution $\mathrm{pH}$ also need to be considered before the matrix interferences can be eliminated. Conveniently, the same conditions that minimize the interference effects enhance the analytical utility of the system: analyte sensitivities were unaltered or reduced by less than a factor of 2 and the fraction of oxide-ion and doubly charged ions are lowered. The overall trends suggest that these benefits derive principally from the effect of solvent load and aerosol characteristics on conditions in the ICP-MS interface.

\section{Acknowledgment}

We thank Peter Richner for his valuable discussion and assistance. The mass spectrometer used in this work was provided by the Perkin Elmer Corp. This study was supported in part by the National Science Foundation through grant $\mathrm{CHE}$ 90-20631.

\section{References}

1. Ure, A. M.; Ellis, A. T.; Williams, J. G. J. Anal. At. Spec* trom. 1988, 3, 175R.

2. Houk, R. S.; Thompson, J. J. Mass Spectrom. Rev. 1988, 7, 425.

3. Hieftje, G. M.; Vickers, G. H. Anal. Chim. Acta 1989, 216, 1.
4. Date, A. R.; Cheung, Y. Y.; Stuart, M. E. Spectrochim. Acta, Part B 1987, 42B, 3.

5. Wilson, D. A.; Vickers, G. H.; Hieftje, G. M. J. Anal. At. Spectrom. 1987, 2, 365.

6. Pickford, C. J.; Brown, R. M. Spectrochim. Acta, Part B 1986, $41 B, 183$.

7. Gray, A. L. Spectrochim. Acta, Part B 1986, 41B, 151.

8. Gillson, G. R.; Douglas, D. J.; Fulford, J. E.; Halligan, K. W.; Tanner, S. D. Anal. Chem. 1988, 60, 1472.

9. Olivares, J. A.; Houk, R. S. Anal. Chem. 1986, 58, 20.

10. Crain, J. S.; Houk, R. S.; Smith, F. G. Spectrochim. Acta, Part B 1988, 43B, 1355.

11. Beauchemin, D.; McLaren, J. W.; Berman, S. S. Spectrochim. Acta, Part B 1987, 42B, 467.

12. Gregoire, D. C. Spectrochim. Acta, Part B 1987, 42B, 895.

13. Tan, S. H.; Horlick, G. J. Aral. At. Spectrom. 1987, 2, 745.

14. Gregoire, D. C. Appl. Spectrose. 1987, 41, 897.

15. Thompson, J. J.; Houk, R. S. Appl. Spectrosc. 1987, 41, 801.

16. Longerich, H. P.; Fryer, B. J.; Strong, D. F., Kantipuly, C. J. Spectrochim. Acta, Part B 1987, 42B, 75.

17. Olesik, J. W.; Williamson, E. J. Appl. Spectrosc. 1989, 43, 1223.

18. Gray, A. L.; Williams, J. G. J. Anal. At. Spectrom. 1987, 2, 599.

19. Vaughan, M. A.; Horlick, G. Appl. Spectrosc. 1986, 40, 434.

20. Vaughan, M. A.; Horlick, G. Appl, Spectrosc. 1987, 41, 523.

21. Wilson, D. A.; Vickers, G. H.; Hieftje, G. M.; Zander, A. T. Spectrochim. Acta, Part B 1987, 42B, 29.

22. Chambers, D. M.; Poehlman, J.; Yang, P.; Hieftje, G. M. Spectrochim. Acta, Part B, 1991, 46B, 741.

23. Deutsch, R. D.; Hieftje, G. M. Appl. Spectrosc. 1985, $39,214$.

24. Smith, T. R.; Denton, M. B. Appl. Spectrosc. 1990, 44, 21.

25. Ross, B. S.; Chambers, D, M.; Vickers, G. H.; Yang, P.; Hieftje, G. M. J. Anal. At. Spectrom. 1990, 5, 351.

26. Dean, J. A.: Rains, T. C. Flame Emission and Alomic Absorption Spectroscopy, Vol. 2.; Marcel Dekker: New York, 1971; p 331.

27, Vickers, G. H,; Ross, B. S.; Hieftje, G. M. Appl. Spectrose. $1989,43,1330$.

28. Zhu, G.; Browner, R. F. J. Anal. At. Spectrom. 1988, 3, 781

29. Hutton, R. C.; Eaton, A. N. J. Anai. At. Spectrom. 1987, 2, 595.

30. Browner, R. F.; Boorn, A. W; Smith, D. D. Anal. Chem. 1982, 54, 1411.

31. Novak, J. W.; Browner, R. F. Anal Chem. 1980, 52, 792

32. Routh, M, W. Spectrochim. Acta, Part B 1986, 41B, 39.

33. Ozeki, T.; Kihara, H.; Ikeda, S. Anal. Chem. 1988, 60, 2058.

34. Razaaiyaan, R.; Olesik, J. W.; Hieftje, G. M. Spectrochim. Acta, Part B 1985, 40B, 73.

35. Borowiec, J. A.; Boorn, A. W.; Deltard, J. H.; Cresser M. S.; Browner, R. F.; Matteson, M. J. Anal. Chem. 1980 52,1054 .

36. Skogerboe, R. K.; Freeland, S. J, Appl. Spectrosc. 1985, 93, 925.

37. Lim, H. B.; Houk, R. S.; Crain, J. S. Spectrochim. Acta, Part B 1989, 44B, 989 .

38. Gray, A. L.: Houk, R. S.; Williams, J. G. I. Anal. At. Spectrom. 1987, 2, 13

39. Chambers, D. M.; Ross, B. S.; Hieftje, G. M. Spectrochim. Acta, Part B, 1991, 46B, 785 .

40. Browner, R, F, Zhu, G. ]. Anal. At. Spectrom. 1987, 2, 543.

41. Koropchak, J. A.; Aryamanya-Mugisha, H. J. Anal. At. Spectrom. 1989, 4, 291.

42. Long, S. E.; Browner, R. F. Spectrochim. Acta, Part B 1988 $43 B, 1461$.

43. Gray, A. L. J. Anal. At. Spectrom, 1989, 4, 371. 